Fecha de recepción: junio 2020

Fecha de aceptación: julio 2020

Versión final: septiembre 2020

\section{Violencia, corporalidad y simbolismo en la novela gráfica memorialista protagonizada por mujeres}

Carmela Artime ${ }^{(1)}$, Montse Gatell ${ }^{(2)}$ y

Teresa Iribarren ${ }^{(3)}$

Resumen: Este trabajo propone una lectura, encuadrada en la intersección entre los estudios de la memoria y de género, de dos novelas gráficas españolas: Cuerda de presas (2005), de Fidel Martínez y Jorge García, y El ala rota (2016), de Antonio Altarriba y Kim. Con el fin de subvertir los relatos de memoria histórica androcéntricos hegemónicos, ambas construyen el espacio político y social de las mujeres durante la Guerra Civil y el franquismo y se hacen cargo de su representación simbólica. Mediante el análisis de diferencias y contactos entre los elementos narrativos de la literatura escrita y los propios del medio gráfico, se demostrará que el impacto determinante del poder patriarcal y de la violencia machista en las trayectorias vitales de las mujeres se representa a través de la corporalidad femenina, persiguiendo activar una respuesta ética por parte del lector. El discurso hermenéutico persigue una finalidad didáctica: siguiendo la pedagogía crítica, se argumentará que las obras ilustran hasta qué punto las relaciones de poder intervienen en la construcción del conocimiento y cómo la literatura gráfica puede ser un instrumento de oposición y subversión de estas relaciones desiguales, propiciando, en este caso, la rehabilitación de un imaginario femenino agentivo.

Palabras clave: Novela gráfica - Memoria - Guerra Civil - Franquismo - Violencia machista.

[Resúmenes en inglés y portugués en las páginas 71-72]

(1) Carmela Artime, Amsterdam University College: c.artimeomil@auc.nl

(2) Montse Gatell, Universitat Oberta de Catalunya: mgatellp@uoc.edu

(3) Teresa Iribarren, Universitat Oberta de Catalunya: tiribarren@uoc.edu 


\section{Introducción}

Durante el primer decenio del siglo XX se promulgaron en España dos leyes de gran calado político, social y simbólico: la Ley Integral contra la Violencia de Género (2004) y la Ley de la Memoria Histórica (2007). Las agrias controversias y el impacto mediático que generaron han ido en aumento a lo largo de los años, a la vez que se han convertido en baluartes de las políticas de izquierdas para situarse a las antípodas de los partidos de derecha o extrema derecha. La Ley de la Memoria Histórica contribuyó a amplificar tempranamente el boom de creaciones culturales de corte memorialista que se desencadenó ya antes de la llegada del cambio de milenio, y que fue propulsado por el gran éxito de novelas como Soldados de Salamina (2001), de Javier Cercas, que recrea la experiencia bélica del novelista falangista Rafael Sánchez Mazas, La voz dormida (2002), de Dulce Chacón, y la serie de relatos y películas sobre las trece rosas -inaugurada por la novela Las trece rosas (2003) de Jesús Ferrero- que, junto con la obra de Chacón, divulgaron las traumáticas experiencias y ejecuciones de mujeres republicanas en las cárceles franquistas (Mitaine, 2010, p. 319). La novela gráfica Cuerda de presas (2005), de Fidel Martínez y Jorge García, se suma a esta serie de relatos carcelarios de mujeres entroncando con la representación gráfica española sobre los horrores bélicos perpetrados en víctimas civiles inocentes, especialmente con los Desastres de la guerra de Goya, y con la deformación y geometrización cubista y expresionista (Crippa 2019; Hafter, 2014) y la saturación cromática de Picasso en el Guernica (Mitaine, 2010, p. 321). En esta recreación coral de testimonios de presas, Martínez y García no solo quieren dar visibilidad a las olvidadas. Triangulando la inserción de la historieta en las creaciones de rehabilitación de la memoria republicana (Matly, 2018), la conexión con la cultura artística española, y la incorporación del imaginario femenino - todavía pobre en los cómics memorialistas españoles- ${ }^{1}$, participan en el proceso de legitimación culturalista aún en curso de la novela gráfica.

El éxito de la producción memorialista — se la ha llegado a calificar de moda literariaes fácil de explicar: el conflicto central de la España del siglo XX se sitúa claramente en la esfera de lo público, lo colectivo, y se vincula a géneros literarios y artísticos y a campos disciplinarios muy institucionalizados. No ha sucedido lo mismo con la ley que se promulgó para proteger los derechos y la integridad física y psicológica de las mujeres porque, contrariamente, se inscribe en el ámbito privado, doméstico, sin una adscripción a géneros ni a ámbitos disciplinarios hegemónicos. La eclosión de obras que abordan la violencia contra las mujeres no llega hasta más tarde, espoleada recientemente por el activismo feminista global del \#MeToo del 2017 y, en España, por las masivas movilizaciones y huelgas del 8-M del 2017 hasta la actualidad. En sintonía con esta nueva ola feminista, los cómics también concurren en la emergencia reciente de obras en el mercado literario global que abordan la violencia machista desde presupuestos ideológicos feministas, cuyas traducciones están viendo la luz en España ${ }^{2}$. En cuanto a la producción española, destaca la novela histórica El ala rota (2016) de Antonio Altarriba y Kim, considerada por Piedras como "un jalón imprescindible del feminismo gráfico" (2017, p. 66). En este trabajo el tratamiento de la violencia en el ámbito doméstico y privado se imbrica con el relato de corte memorialista, presentando en este caso la historia de vida de una mujer humilde durante 
la Guerra Civil y la posguerra. El cómic, de concepción irónicamente androcéntrica, recrea la biografía de la madre de Altarriba, la sumisa y callada Petra.

Cuerda de presas y El ala rota, dos títulos que evocan la privación de libertad, no solo persiguen contrarrestar una narrativa y una iconografía histórica masculinizada que ha priorizado la perspectiva militar ${ }^{3}$. Los autores, que intervienen en las controversias memorialistas y feministas denunciando las múltiples violencias de que fueron víctimas las mujeres, ocultadas bajo un silencio invisibilizador durante el franquismo, la transición y hasta bien entrado el siglo XXI, también quieren contribuir simbólicamente al proceso de reparación histórica para con españolas como la sufrida Petra ${ }^{4}$. Por ello cabe poner de relieve que debemos acercarnos a estas novelas gráficas históricas teniendo en cuenta que son a su vez objetos históricos (Malty) que incorporan información del actual contexto político, social y cultural global y nacional —en el que las dos leyes siguen siendo objeto de controversias y de instrumentalización ideológica.

Como en todos los ámbitos disciplinarios, la incorporación de la perspectiva de género como marcador social diferencial en los estudios críticos de la memoria, y más especialmente en la novela gráfica, ha sido lenta e incompleta. A pesar de que ya han empezado a realizarse aportaciones sobre el tratamiento de las mujeres en la novela gráfica memorialista (Auroy, 2019; Behiels, 2020; Crippa, 2019; Gyssels, 2019; Mitaine, 2010), aún quedan pendientes muchas tareas de análisis. En el actual contexto de la prescriptiva educación en la igualdad y el respeto hacia todos los géneros — que creemos que debe afrontarse desde la pedagogía crítica, porque es aquella que "arroja luz sobre la relaciones entre conocimiento, autoridad y poder" (Giroux, 2018, p. 38)—, una de las más urgentes es examinar cómo se ha plasmado la memoria de una tradición patriarcal que somete a las mujeres a través de la violencia directa y simbólica. Teniendo en cuenta que el franquismo articuló un programa de sometimiento del cuerpo de la mujer con un explícito fin de nacionalización (Bergès, 2012), pensamos que es especialmente oportuno focalizar el análisis en la corporalidad femenina. Así, nuestra investigación, encuadrada en la intersección entre los estudios de la memoria y de género, y asumiendo el espíritu de la crítica democrática (Said 2004), pretende indagar en las estrategias de representación de las violencias infligidas en unos cuerpos femeninos caracterizados, solo a priori, por la vulnerabilidad y la precariedad (Butler 2009) en dos novelas gráficas memorialistas protagonizadas por mujeres.

\section{La memoria de las mujeres y su representación literaria. Aproximación teórica}

La Guerra Civil española es, sin lugar a dudas, uno de los grandes acontecimientos históricos de la Europa del siglo xx. Las consecuencias de la conflagración bélica, tanto políticas como sociales, culturales y económicas, no solo impactaron en el Estado español, sino que se vincularon también a la Segunda Guerra Mundial y a la construcción de la nueva Europa surgida de la catarsis provocada por la gran guerra. El carácter eminentemente político y social de la Guerra Civil y la circunstancia de que, una vez finalizada, se instaurara una dictadura fascista de más de tres decenios, avalan el hecho de que estas especificidades sin- 
gularizan las actitudes respecto a la memoria. En este sentido, las generaciones posteriores a la guerra muestran un interés por el conflicto y su memoria y, así mismo, por la demanda de justicia y la exigencia de devolver la dignidad a las víctimas, posicionamientos que surgen de la violencia que los vencedores fascistas ejercieron sobre los vencidos republicanos y su memoria durante la posguerra. Esta violencia es constitutiva de los traumas colectivos que, según Julio Aróstegui (2006, pp. 59-60), conforman la base del interés por la memoria de la guerra y la dictadura en lo que ha venido en llamar "el tercer gran ciclo histórico" de la contemporaneidad española que arranca de la Transición.

La literatura desempeña un papel principal en los procesos colectivos de recordación ya que, como medio de memoria - en el sentido de artefacto que permite la formación y la transmisión del conocimiento del pasado común en contextos determinados, según los Cultural Memory Studies - proporciona construcciones sociales y culturales que modelan la percepción, el pensamiento y el imaginario sobre el pasado y sobre el presente desde el cual se recuerda. Esta formulación se basa en el hecho de que no todas las fórmulas de recordación que se dan en contextos socioculturales son producto de experiencias directas, sino de representaciones que han sido transmitidas a través de estos medios. Estos procesos de transmisión son altamente selectivos y crean versiones del pasado según las condiciones y las necesidades del presente. Como sistema simbólico, pues, la literatura se convierte en un medio de reflexión crítica sobre el pasado y sus representaciones con un poder determinado para intervenir en la modificación del imaginario colectivo y en la construcción del sentido de todo ello a través de la configuración de nuevas memorias. Mediante los epígrafes "discursos sobre el pasado", "novela de la memoria", "relato de la memoria", "narrativa del recuerdo", "narrativa testimonial" o "narrativa de la memoria", se etiquetan los discursos que reconstruyen la memoria a través de relatos literarios que, en España, protagonizaron el boom de la literatura sobre la Guerra Civil a partir de los años 1990. Esta explosión responde, en parte, al auge del interés por la memoria de la guerra y el franquismo en el ámbito social y político y culmina, en la acción reivindicativa y política, con la aprobación de la Ley de la Memoria Histórica. Se trata del corpus de obras propias de la generación literaria de los "nietos de la guerra" que sucedió a la de los "hijos de la guerra" y a los testimonios directos.

Es en este contexto que aparecen las obras protagonizadas por las víctimas, las que Carlo Ginzburg llama "microhistorias", olvidadas y silenciadas durante décadas. A la par del cuestionamiento de los relatos historiográficos institucionales, estas propuestas literarias defienden que la ficción constituye un dispositivo cultural adecuado para romper la hegemonía de aquellos. Consiguientemente, se reconoce la ficción como un agente relevante y legítimo en el proceso de reconstrucción del devenir histórico, incluida aquella que no pertenece al canon de la literatura de guerra.

Queda fuera de toda duda que las mujeres han protagonizado (y escrito) buena parte de estas microhistorias que no han contado con el interés de la institución académica ni del público durante decenios. Desde la fecha del conflicto hasta la década de los noventa, la memoria de la Guerra Civil se ha construido mayoritariamente a través de los relatos bélicos masculinos, mientras que las mujeres, protagonistas de las historias de la retaguardia y la represión, no han contado con la posibilidad de transmitir su experiencia al carecer esta del espíritu épico y el aura heroica asociados al conflicto bélico y, también, a causa del si- 
lenciamiento de la voz femenina en el sistema patriarcal. Por esta razón, el establecimiento de la relación entre la memoria y el género es conflictiva, ya que las disciplinas que se ocupan de ella, los estudios de la memoria y los estudios de género, tienden a esencializar el género, de un lado, y a representar la memoria únicamente como imitación o símbolo, de otro (Troncoso y Piper, 2015, pp. 65-66). Este conflicto se resuelve con el análisis de las relaciones sociales entre los sexos en clave de relación de poder y de dominación, teniendo en cuenta, con Bourdieu, que se parte de un patrón de relaciones asimétricas entre los individuos y entre los grupos sociales y, en el caso de la dominación masculina de las mujeres, se trata de una dominación que cruza diferentes campos: el económico, el social, el cultural, el de la visibilización y, también, el de su representación literaria. Teniendo en cuenta el carácter constructivo y selectivo de la memoria, la literatura, como sistema simbólico, se convierte en un medio de reflexión crítica sobre el pasado y sus representaciones. En este contexto, autores como Di Liscia (2007) analizan la represión de las mujeres en escenarios traumáticos y concluyen que el hecho de privilegiar el sufrimiento de las mujeres como madres o víctimas de la violencia sexual elimina de la construcción hegemónica de las memorias su imagen de resistencia y de heroísmo. Este es un planteamiento que se articula a partir del análisis de las representaciones del cuerpo de las mujeres, sus maternidades y el cuidado de los demás. Por otro lado, Leonor Arfuch (2013) elabora, a partir del uso feminista de la noción de agencia, la idea de la resistencia a la victimización para que las memorias de la violencia política se puedan pensar desde una ubicación diferente a la de víctima. Finalmente, en la necesidad de establecer la naturaleza propia de los conceptos de víctima y testimonio, teniendo en cuenta que son figuras altamente masculinizadas, se encuentra la necesidad de contar con las mujeres en cuanto a sujetos políticos, es decir, en un espacio público concreto y con propiedad enunciativa. Es, por tanto, desde esta perspectiva que es necesario analizar cómo se enuncian, dentro del sistema simbólico literario, las mujeres y sus memorias, y de qué modo su testimonio — directo o mediatizado- se inscribe en la representación de sus cuerpos.

\section{La mujer según el franquismo}

Aunque la representación de la mujer en el cómic memorialista en España ha adquirido una mayor presencia en los últimos años, los personajes masculinos siguen protagonizando la gran mayoría de los relatos en los que la historieta del siglo XXI rememora la Guerra Civil ${ }^{5}$ la posguerra. Los personajes femeninos se relegan casi siempre a un segundo plano; son comúnmente amantes, madres o hermanas que ocupan espacios íntimos, principalmente el hogar. Contrariamente, Cuerda de presas y El ala rota crean un espacio de protagonismo para las mujeres y exploran las particularidades de la resistencia femenina —así como El ángel de la retirada, de Serguei Dounovetz y Paco Roca (2010). Ambos trabajos muestran diferencias importantes - el primero es un relato colectivo que se ubica en el ámbito de lo público, y el segundo constituye un relato personal e individual que se desarrolla en un entorno privado, una microhistoria-, pero los dos abordan temas que dan forma al actual imaginario de la memoria de las mujeres durante el franquismo. 
La infancia (Hafter, 2014), la maternidad, la sexualidad, su agencia política, la represión, su relación con las siguientes generaciones y con los agentes de poder, son todos ellos elementos presentes en estos trabajos. De la presentación de cada uno de estos temas trasciende una conexión con la figura del cuerpo femenino y el acercamiento que el régimen, las protagonistas y otros agentes sociales establecieron con él.

En el marco de las convicciones de la falange, destiladas de los seculares mandatos católicos, ser madre y esposa debían ser las mayores aspiraciones de la mujer. En consecuencia, la educación en relación con sus cuerpos se centraba en dos funciones elementales prescriptivas: la reproducción y el placer del cónyuge. Pero paradójicamente, la educación femenina promulgaba el distanciamiento de la mujer respecto a su cuerpo y la consecución de la virtud ignorando las propias necesidades y el propio placer. En definitiva, se perseguía la desexualización del cuerpo femenino de su dimensión erótica (Bergès, 2012). Teniendo esto en cuenta, Aurora Morcillo concluye que durante la época de gobierno de Franco hay un intento de uso del cuerpo femenino como figura al servicio del ideario franquista que ayuda a dar forma a la nación y a crear estrategias de control. Morcillo desarrolla la relación simbólica entre el régimen franquista y el cuerpo femenino, entendiendo el cuerpo de la mujer como metáfora de la nación: "el concepto de nación se transmuta en la figura física de la mujer con todas las cualidades que se le asocian: maternidad, vulnerabilidad, fertilidad" (2016, p. 8). Mediante la humanización del concepto de nación que desarrollaba el régimen se conseguía, por contraposición, la deshumanización de la enemiga republicana, también simbolizada en la figura del cuerpo femenino: "En España, el régimen de Franco intentará refundir la imagen de la mujer liberada que había traído la Segunda República, transformándola en la de una 'auténtica mujer católica', piadosa, maternal y plenamente entregada” (Morcillo, 2016, p. 9).

Las ideas con las que el franquismo daba forma a la imagen de la enemiga se centraban en la transformación del uso de su cuerpo. A ojos del fascismo, la mujer republicana no solo era una mujer rebelde y activa políticamente: se la representaba como sucia, promiscua, sexualmente desviada y masculinizada. Las rojas encarnaban el exceso y el pecado, y eran dueñas de una conciencia de su propio cuerpo que las trasladaba hacia lo indeseable, hacia lo bárbaro, lo animalizado. En consecuencia, tal como veremos en Cuerda de presas, el suyo es un cuerpo que debe ser domesticado mediante distintas estrategias de violencia como el castigo, la reclusión, la represión, el control, la disciplina y el trabajo.

\section{Cuerda de presas}

Cuerda de presas es una colección de once microhistorias protagonizadas por presidiarias. Los relatos, cronológicamente inscritos aproximadamente en el arco temporal del 1936 al 1942 (Crippa, 2019), transcurren en el marco diegético de distintas cárceles. Con la conjunción de estas historias se conforma el relato colectivo de reas republicanas que, por afiliación política suya o de algún familiar, fueron capturadas y encarceladas, y muchas de ellas asesinadas. Las tenebrosas y perturbadoras vivencias carcelarias se expresan con una subrayada oscuridad gráfica; en una monocromía de negro, sin apenas matices, se recrea la claustrofóbica sensación de encierro a la que hacen referencia las historias. Además, el 
trayecto de una cárcel a otra — que también hace el lector al pasar de un relato a otroconecta con uno de los temas que denuncia y discute este trabajo, confiriéndole así un carácter unitario, y que da sentido al título de la novela: el traslado de las presas. Porque los cómics sobre la cárcel —igual que los que abordan el exilio republicano— lo que plasman es un itinerario, como indica Matly (2018).

Si bien el régimen de Franco usa una determinada imagen del cuerpo femenino como elemento ejemplificador y adoctrinador al servicio de su imaginario político, Cuerda de presas parte de esa misma imagen para, mediante la contraposición, proponer una figura de la mujer republicana que, manteniendo el enfoque en el cuerpo, muestra un esfuerzo por deshacerse de aquellos clichés impuestos sobre el mismo. Martínez y García exponen unas mujeres con agencia política, cuyos cuerpos, a pesar de haber sido receptáculo de múltiples violencias, son también sus herramientas de liberación. En su muestra de cómo el cuerpo femenino fue objeto de represión y torturas, el cómic denuncia tanto la simbología creada como las prácticas de castigo a las que eran sometidos esos cuerpos.

El estereotipo de la mujer republicana como "sucia" se discute en el relato "El traslado", en el que las convictas son trasladadas de una cárcel a otra en trenes de mercancías y en condiciones de extrema insalubridad. Sus cuerpos son degradados hasta la cosificación: "Dos días en aquel horno, oliendo a sudor y excrementos" (Martínez y García, 2005, p. 49), recuerda una voz narrativa que, junto a sus compañeras, es deshumanizada no solo por medio de la suciedad descrita, sino también a través de la imagen de los niños que jugaban a tirarle piedras y a observar cómo pasaba ante sus ojos lo que ellos perciben como mercancía. Previamente, en el relato "El cuarto de la escalera" los autores abordan la idea de la mujer republicana como promiscua. "Parece una fábula: el cerdo y la zorra" (Martínez y García, 2005, p. 30), murmuraban las reas al ver pasar a su compañera Luisa Álvarez caminar con uno de los guardias hacia el cuarto que da nombre al relato. Luisa es la comidilla de la cárcel de Albacete y la única de sus compañeras a la que los guardias no le raparon el pelo, siendo eximida del castigo por rendirse a ser objeto de abusos en esa habitación a la que el guardia la llevaba. El desprecio hacia Luisa evidenciado en el uso de la palabra "zorra" parece hacer alusión a las violaciones y al discurso franquista que pretendía animanizarlas; pero la historia nos muestra que hay una segunda connotación de talante político, ya que Luisa se había rendido durante los crueles interrogatorios a los que las presas eran sometidas. La narradora de esta historia lo explica que Luisa había perdido la batalla contra ella misma en aquellos interrogatorios, y la consecuencia es doble: el desdén de sus compañeras y la tiranía por parte de las autoridades carcelarias, todos hombres, que agredían sexualmente su cuerpo.

Además de las violaciones sufridas por las presas en las cárceles franquistas, este relato denuncia los castigos físicos que hoy consideramos crímenes de guerra, las torturas. En su memoria, la voz narrativa que recuerda desde el presente guarda una viva y traumática imagen del dolor y del miedo y, llevándose la mano a la cabeza en un gesto de postración física, como si su cuerpo todavía reviviera el sufrimiento, la narradora visualiza su propio cuerpo desnudo y maniatado, indefenso y extremadamente vulnerable, con sus pechos expuestos sobre los que aplicaban descargas eléctricas, castigando así también de manera simbólica su sexualidad (véase Figura 1). 

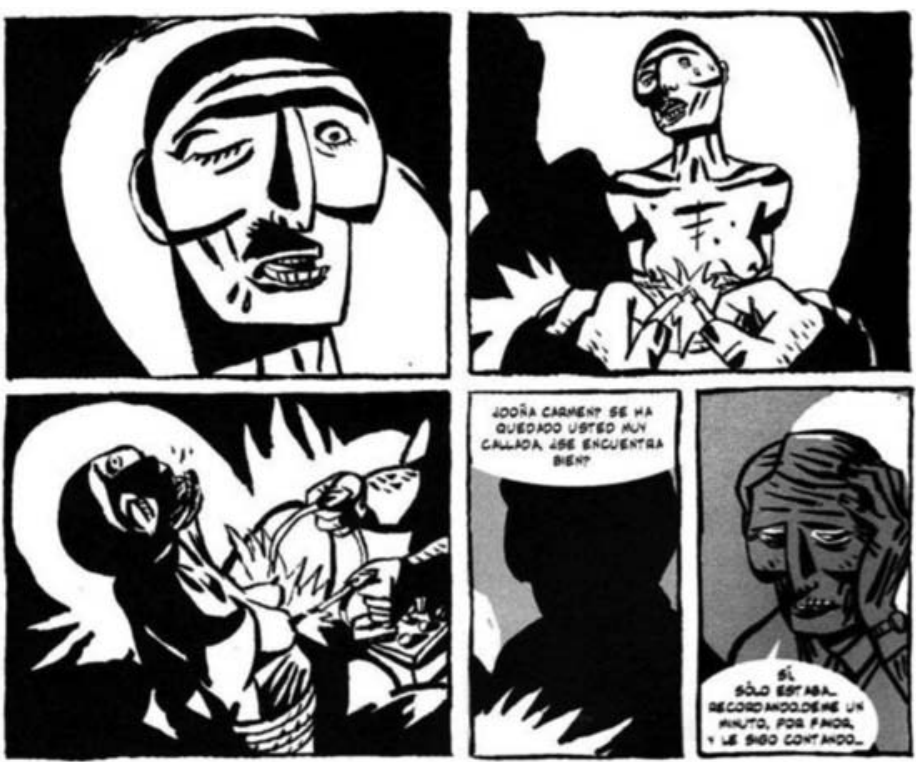

Figura 1. García, Jorge y Fidel Martínez. Cuerda de presas. Astiberri, 2005, p. 31.

En estas mismas viñetas, no solo observamos un cuerpo agredido, sino que vemos dibujado el rostro del dolor cuya intensidad llega a deformar y a deshumanizar a la víctima. Un primer plano enfrenta al lector a ese dolor. Los ojos deformados, la boca torcida y los huesos de la cara marcados recuerdan a una calavera de la que, paradójicamente, emana la vida que hay en la angustia y el sufrimiento físico. Como en el Guernica, la deformación de filiación cubista y expresionista persigue generar una experiencia nada fácil para el que observa, y de la que se espera una reflexión ética y política.

Por medio de la historia de Luisa y de la imagen de los recuerdos de quien la narra, Cuerda de presas expone también la simbología del castigo de rapar la cabeza a las mujeres republicanas, correctivo común durante los primeros años de la dictadura. Este castigo, que en principio parece inofensivo en comparación con otras formas de sanción habituales de la época, supone una mutilación simbólica de la femineidad de estas mujeres y trae de nuevo a colación la imagen de estas como sucias, ya que supuestamente se les rapaba la cabeza por razones higiénicas. Al despojarles de su pelo —uno de los símbolos tradicionales de lo femenino- se perseguía la masculinización y estigmatización de la mujer, a la que también se hace referencia en el relato "Fuegos". En este relato, dos personajes comentan, en alusión a un grupo de republicanas que pasaban "- ¿Ves esas mujeres?, —iQué mujeres? Yo solo veo reas” (Martínez y García, 2005, p. 80). La masculinización de las mujeres 

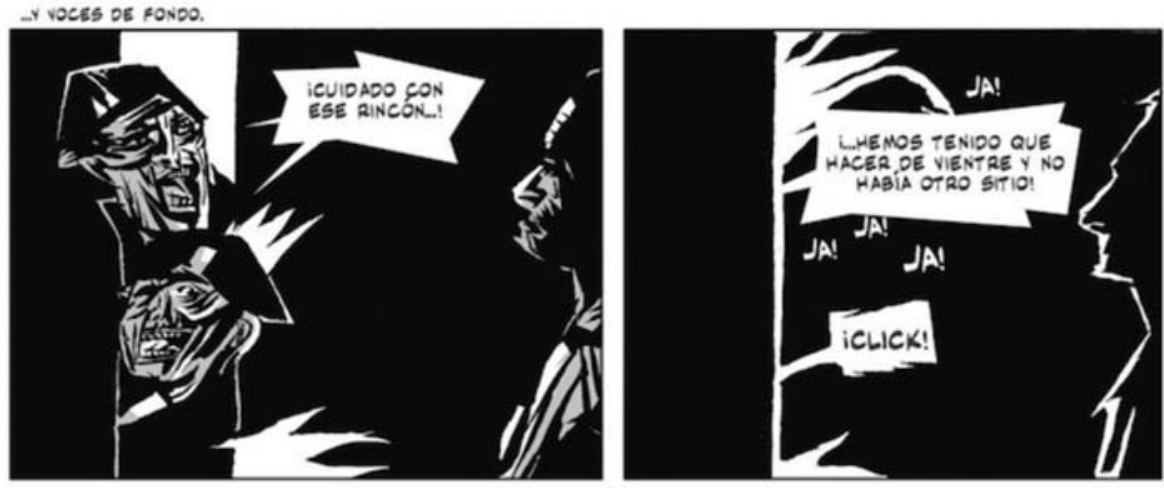

Figura 2. García, Jorge y Fidel Martínez. Cuerda de presas. Astiberri, 2005, p. 48.

conecta en "Fuegos" con el estigma de la desviación sexual, expuesto en este relato a través de la historia de amor de Matilde García Santisteban y Nieves Álvarez Martín. La historia muestra cómo las dos reas son castigadas por su relación: torturadas y aisladas por las autoridades y despreciadas por sus compañeras de prisión: "Dicen que es una invertida... que la pescaron haciendo cochinadas con su 'novia' en los serivios del penal de Cuenca" (Martínez y García, 2005, p. 82). Se presentan, en pocas palabras, como mujeres deshumanizadas, con una femineidad deformada, mujeres que no son mujeres, porque no mantienen relaciones con hombres, o que se perciben como simples presidiarias sin identidad o como mercancía.

Mediante este intento de deformación de los cuerpos femeninos por parte de los poderes franquistas —en su uso como ejemplificación de lo indeseable_Cuerda de presas muestra que, contrariamente, se consigue una deformación del régimen y no de la mujer republicana. Los cuerpos castigados de estas mujeres funcionan así como los espejos cóncavos de la calle del $\mathrm{Gato}^{6}$. En ellos vemos reflejado el franquismo que, siguiendo con la símil valleinclanesco, se muestra deformado, absurdo, animalizado, grotesco y carente de forma humana. En consecuencia, los mismos cuerpos que aparentemente se muestran victimizados funcionan en realidad como elementos liberadores. Cuerda de presas desvela, de esta forma, unos cuerpos que se mueven a través del baile y el deporte, ayudando así a hacer más llevaderas las condiciones de precariedad, humillación y maltrato en las que viven; y son, además, cuerpos-espejo en los que el reflejo de sus opresores muestra a violadores, seres deformados y con actitudes sórdidas. El narrador gráfico, cargando las tintas negras, es el principal encargado de exponer esa deformación (véase Figura 2).

Los guardias que en "El traslado" defecan dentro de los vagones de las presas son solo dos cabezas. Su gesto y facciones torcidas se enfrentan directamente al gesto digno y hierático de la presa que los mira. Por su parte, el violador de Luisa representa la promiscuidad que 
se le adjudica a las mujeres. De él vemos varias veces su sombra, desprovista de forma humana, tan expresionista, casi perdiendo la cabeza entre los hombros y evocando la forma de un simio; y frente a él, su víctima resiste el desprecio de sus compañeras que la castigan por haberse rendido frente a la presión del enemigo, poniendo así de relevancia la agencia política de estas mujeres por encima de su victimización.

Finalmente, los agresores de Matilde y Nieves, y la representación de la Iglesia que las juzga como invertidas, se debilitan ante un huracán y un incendio. En un acto de justicia poética, donde la propia naturaleza termina relegando a los opresores a un segundo plano, se crea un espacio para que las protagonistas - a las que se les adjudica entidad mediante el uso de su nombre completo, con nombre de pila y apellido- puedan centrarse la una en la otra. De esta manera, la corporalidad en Cuerda de presas no solo tiene como objetivo denunciar la cosificación, la degradación, los sufrimientos y las torturas físicas perpetradas sobre las prisioneras de guerra, sino que, lejos de caer en la pasividad victimista, también quiere mostrar su resistencia: ellas, que asumen las consecuencias de las batallas perdidas, humanizan estas experiencias a través del amor y del dolor que todavía recuerdan, y se mantienen firmes ante sus enemigos, sus convicciones políticas y sus sentimientos.

\section{El ala rota}

El ala rota expone la otra cara de la misma moneda a través del personaje de Petra, la madre de Antonio Altarriba. Si bien las mujeres republicanas de Cuerda de presas representaban lo indeseable y, consecuentemente, su cuerpo era castigado, El ala rota muestra un modelo de mujer acorde a la prescripción franquista, en el que el cuerpo, además de físicamente hostigado, también es reprimido y controlado: de ahí que el título del libro invoque metafóricamente a la privación de libertad (Celso \& Carlos, 2016).

La publicación de El ala rota está estrechamente ligada a El arte de volar, la primera de las obras del díptico de memoria familiar ficcionalizada (Suárez, 2018, p. 298) del que forma parte $^{7}$. Posiblemente, muchos de los lectores de El ala rota conocen el personaje de Petra antes de comenzar la lectura, porque aparece como personaje secundario en ese primer trabajo. Por lo tanto, ese mismo lector abre la novela gráfica con la idea predeterminada de que Petra es "un elemento subsidiario, antipático, beato y gris, del que apenas conocemos su frigidez, su insensibilidad y su cerrilidad" (Piedras, 2017, p. 66). Sin embargo, las primeras páginas de El ala rota desvelan ya la complejidad del relato que por mediación filial nos llega de Petra. La novela, además de una historia de ámbito privado, plasma las experiencias vitales del sector de la sociedad al que este personaje representa, adentrándose en "el laberinto psicológico de las mujeres españolas de clase baja en el s.XX” (Piedras, 2017, p. 66). La obra arranca con Antonio Altarriba, que es quien articula la voz narrativa, descubriendo en el lecho de muerte de su madre una lesión en el brazo: esto es, el ala rota (metáfora y literalidad física), que ella había ocultado durante toda su vida. La unidad semántica que constituye la primera página, que abre con una viñeta muda que muestra el brazo de la anciana con hematomas y se cierra con la imagen de sorpresa de su hijo, pone en un primer plano inaugural el cuerpo de la mujer como objeto de maltrato e invisibilidad (véase Figura 3). 


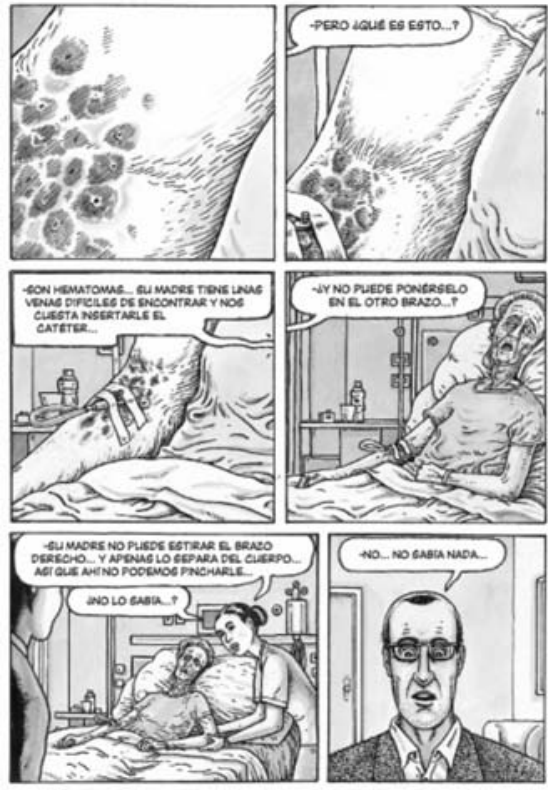

Figura 3. Altarriba, Antonio y Kim. El ala rota. Norma Editorial, 2016, p. 5 .

En las siguientes páginas el lector descubre que la ignorancia de Altarriba hijo sobre el cuerpo y las experiencias vitales de su madre, o quizás aún más sorprendente, la ignorancia del marido sobre las mismas, son solo síntomas de la alienación que el régimen había establecido entre las mujeres y su propio cuerpo, obstaculizando la autoconciencia corporal. "Desde siempre" (Altarriba y Kim, 2016, p. 6) le dice la madre a Altarriba cuando este le pregunta desde cuándo no puede mover el brazo. Estas palabras se repetirán en la cabeza del personaje y lo empujarán a descubrir qué significa ese "siempre". La revelación in extremis del "ala rota", que activa la conciencia en el narrador de la miopía marital y filial respecto a la corporalidad y el sufrimiento de la esposa y de la madre respectivamente, constituye el motor narrativo. Desde las primeras páginas, el lector sabe que asiste a un relato de reparación filial y colectiva simbólica, porque la presentación de la historia de la madre establece una clara relación sinecdóquica respecto a otras tantas figuras subalternas sin voz a las que Petra representa.

El narrador gráfico nos da las claves para entender la dimensión de esta invisibilidad. A través de fotografías ${ }^{8}$ que reflejan diferentes momentos de la vida de Petra, el lector observa cómo el personaje "siempre" hizo una vida aparentemente normal. Pero este ejercicio de revisitación vital — ficcionalizado— permite descubrir que, desde niña, Petra tuvo que desarrollar estrategias gestuales para impedir que la deformación de su cuerpo no fuera un hándicap para llevar a cabo los quehaceres propios de su género. Con un espíritu de resiliencia extraordinario, la sufrida y hacendosa Petra trabajaba sin descanso, se consa- 
graba al cuidado de los otros (padre, hermanos, hijo) y se encargaba de las tareas del hogar. Como nunca se quejó de sus dificultades, la lesión pasó desapercibida, haciendo invisibles su cuerpo y su dolor, incluso para ella misma.

Inevitablemente, por la condición de secuela con respecto a la historia del padre de Altarriba que se cuenta en El arte de volar, el personaje de Petra se percibe subordinado a este. El inevitable cotejo de los mismos títulos del díptico pone en relieve una significativa carga simbólica en oposición binaria: mientras la primera, dedicada al padre, vincula el hombre a la máquina, a la heroicidad, al dominio frente a la naturaleza, a la libertad y al valor tan culturalmente positivo de la palabra "arte", la segunda, dedicada a la madre, vincula la mujer a la animalidad, a la fragilidad del pájaro que cuida del nido, a la incapacidad y a la privación de libertad. Debe destacarse que, al haber un cambio de género, en El ala rota no se representa una historia de guerra al uso, sino como una historia de vida en un contexto bélico. Sin embargo, el relato sigue teniendo un enfoque androcéntrico: no solo es masculina la voz narrativa; la misma estructuración de la historia de Petra señala que, de acuerdo con el secular sistema patriarcal, su existencia fue totalmente determinada por los hombres que formaron parte de su vida. Con una carga irónica que aspira a denunciar la subordinación de la mujer en la España tradicional y franquista, la novela se organiza secuencialmente en función de los hombres que gobernaron las diferentes épocas de la vida de Petra: Damián, su padre (1918-1942); el general Juan Bautista Sánchez, para el que ella trabaja (1942-1950); Antonio, su marido (1950-1985); y finalmente, Emilio, con el que establece una relación al final de su vida (1985-1998). Los nombres de ellos en las rúbricas de los capítulos de la novela contribuyen a que Petra parezca, en ocasiones, un personaje secundario en su propia historia - pero nunca como víctima pasiva. Además, también dan la clave del sentido metafórico del ala rota, que representa la privación de libertad y la violencia de la dominación ejercida sobre la mujer en el patriarcado, siempre sometida a los dictados, necesidades y deseos del hombre. Este desplazamiento a un segundo plano se evidencia tanto a partir de la estructura del trabajo y del cuerpo invisibilizado como del silencio de Petra, al que se hace referencia en varias ocasiones.

En virtud de su discreción, Petra consigue el puesto de mayor responsabilidad nada más llegar a la casa en la que trabaja, y se encarga ella personalmente de servir a los asistentes a las reuniones secretas organizadas en casa del general Sánchez González, donde se conspira para revocar a Franco en beneficio de la monarquía. El peso del silencio en la historia de Petra es evidenciado textualmente en varias ocasiones por el general y su mujer e incluso por la propia Petra, que lo asume como una obligación: "No me fijo en medallas ni en galones... y, si me fijo, no lo cuento por ahí... tú deberías hacer lo mismo..." (Altarriba y Kim, 2016, p. 113). Pero además, como bien nota Vanessa Auroy, este silencio es también enfatizado visualmente, ya que en comparación con El arte de volar, donde no existen las viñetas mudas, la historia de Petra cuenta con numerosas imágenes silenciosas (2019, p. 52). Y es precisamente ese silencio el que le atribuye a Petra la poca entidad política de la que goza el personaje durante su historia, ya que su papel en el entramado político de la época consiste en proteger, no tanto por convicción ideológica sino por responsabilidad profesional, las conspiraciones que sucedían en aquellas reuniones que pretendían restaurar la monarquía. 
El de Petra es un cuerpo cargado de memoria que también habla de la relación que los hombres de su vida establecieron con él. La lesión en el brazo cuenta la historia de agresión física por parte de su padre, quien ante la muerte de su mujer durante el parto de Petra, en un ataque de ira intenta matarla golpeándole con una piedra. La violencia machista es, además, denunciada por medio de la historia de Sara, una amiga de Petra que es maltratada por su marido. Llama la atención la manera casi casual en la que las amigas comentan lo sucedido: “¿Qué te ha pasado? ¿Otra vez Paco? Esta vez te ha pegado fuerte...” (Altarriba y Kim, 2016, p. 166) le dice Petra a su amiga al notar sus heridas. Las amigas parecen asumir, influenciadas por sus creencias religiosas y los adoctrinamientos del estado, que su relación con el hombre es de sumisión: "—¿¿Se lo has contado a alguien? - A mi confesor. - ¿Y qué dice? -Que tenga paciencia... que Paco también lo pasa mal en el trabajo y de alguna manera tiene que desahogarse... que es mi marido... que le debo obediencia y respeto..." (Altarriba y Kim, 2016, pp. 166-167). La Iglesia, a la que las tías de Petra recurren para su salvación y protección, justifica los actos de violencia hacia sus cuerpos, incluso el de la agresión que de bebé marcó su vida. En una conversación con sus tías, el cura del pueblo plantea la imperiosa necesidad de un bautizo para que el cuerpo y el alma de Petra sean purificados y perdonados: "Hay que bautizarla enseguida... así limpiaremos todas sus culpas... porque su nacimiento ha provocado la muerte y el pecado..." (Altarriba y Kim, 2016, p. 25), y así, al hacerla responsable de la muerte de su madre y dándole la razón al padre, allana el camino para el perdón del agresor.

Todas estas vivencias de Petra - la muerte de su madre durante el parto, la relación de dependencia con la Iglesia, y la agresión sexual que sufre durante su adolescencia- determinan cómo la protagonista entiende su sexualidad. Petra es una mujer atractiva para los hombres y en varias ocasiones se hace referencia a su sensualidad, tanto de manera gráfica como textual. Sin embargo, para Petra, el sexo no es una fuente de placer, sino un acto de violencia (Auroy, 2019, p. 59); por eso el hombre es comúnmente representado como agente de esa amenaza. En consecuencia, ella siente el instinto de defenderse cuando el acoso le llega por parte de extraños, e incluso llega a rechazar las relaciones íntimas de su vida con su marido: "Antonio, no quiero volver a hacerlo. ¿El qué? Ya sabes, eso." (Altarriba y Kim, 2016, pp. 150-151). Petra se distancia así de cualquier tipo de contacto carnal y solo lo retoma al final de su vida cuando accede a un acercamiento con Emilio. Es precisamente en esa distancia donde Petra encuentra su particular espacio de resistencia, ya que no se pliega al supuesto deber de la mujer de complacer al cónyuge ante sus necesidades sexuales sino que, por el contrario, respeta su falta de deseo por su marido y los miedos que el acto sexual provocan en ella.

Entroncando con el secular lugar común del hogar como espacio carcelario para la mujer, en El ala rota encontramos un cuerpo capturado, controlado y objeto de distintas formas de violencia — que se solapan o encadenan a lo largo de casi toda su vida — en el ámbito de lo doméstico, tanto o más que el cuerpo de las reas que estaban entre rejas en Cuerda de presas. Sin embargo, a pesar del ala rota, Petra encuentra un espacio de agencia, de libertad personal y de autoridad a través de la protección de su cuerpo agredido, superando así la vulnerabilidad en la que se inscribían las mujeres de su condición. Si bien las restricciones impuestas por la Iglesia y el régimen franquista desplazan ese cuerpo a un segundo plano, incluso para la propia protagonista, que se aleja del mismo, es ese mismo distanciamiento 
el que, finalmente, la hace dueña de este, y le proporciona el control y la entidad necesaria para convertir su corporalidad reprimida en un baluarte simbólico de poder.

\section{Conclusiones}

Cuerda de presas y El ala rota entroncan, solo en parte, con aquellas obras literarias memorialistas que, décadas después de la Segunda Guerra Mundial, consagran el "relato victimista en el lugar del relato heroico, en la cima de una jerarquía simbólica”, testimoniando así "que entre nosotros se ha reforzado la idea de justicia", según Todorov (2014, p. 94). Si afirmamos que participan de esta operación testimonial parcialmente, es porque tal y como hemos intentado demostrar, ambos trabajos rehúyen el victimismo en su compromiso por denunciar y reparar simbólicamente el olvido de las mujeres en los discursos históricos y culturales hegemónicos amparados por el patriarcado. Mediante un grafismo que interpela la conciencia ética y política del lector, estas propuestas literarias dan visibilidad a las mujeres como sujetos con agencia en el sentido que, unas y otra -las represaliadas republicanas y Petra - resisten y superan la violencia y el sometimiento al silencio y la invisibilidad a través de gestos de autoafirmación que pasan, mayoritariamente, por el establecimiento de una estrategia de supervivencia. Asimismo, Cuerda de presas y El ala rota se constituyen en medios para la representación de las distintas violencias - física, psicológica, institucional, simbólica - ejercidas sobre las protagonistas a través de la manipulación de sus cuerpos. Ambas novelas hacen prevalecer el discurso del sufrimiento y la resistencia a la violencia por encima de los discursos de las voces subalternas de las mujeres que, educadas bajo los preceptos católicos y fascistas, fueron también condenadas al silencio y relegadas a una vida de obediencia y sumisión.

En contraposición con el relato franquista sobre las mujeres republicanas, que las deshumaniza, el relato en el cómic contemporáneo les devuelve su condición humana y la dignidad al convertirlas en protagonistas de historias sobre la Guerra Civil y el franquismo, contextos dominados por el protagonismo masculino. En el caso de Cuerda de presas, la novela también les devuelve la entidad política. Ante la agresión hacia los cuerpos femeninos, comúnmente masculina, ambas novelas muestran dos maneras de enfrentarse a la violencia y de liberarse de sus opresores. Si bien las reas de la obra de García y Martínez aceptan su cuerpo y se acercan a él, conectando más íntimamente con las sensaciones que este genera, en la protagonista de Altarriba y Kim observamos el movimiento contrario, de alejamiento, hasta el punto de ignorar la propia corporalidad y renunciar a la sexualidad. Es en esa distancia que Petra encuentra su espacio de resistencia. Fuente de sufrimiento en todas ellas, los cuerpos son lienzos en los que se inscribe la memoria de los efectos de la guerra y la represión en mujeres civiles.

En sintonía con algunos de los presupuestos sociales y políticos feministas actuales, Martínez y García, y Altarriba y Kim introducen el imaginario femenino en el constante y controvertido proceso de reconfiguración de la memoria histórica alineándose, a su vez, en el rechazo a todo tipo de violencia contra las mujeres. Igual que otros autores de cómic sobre la Guerra Civil, como bien observa Michel Matly (2018), apelan a la conciencia crítica 
del lector, a quien quieren emocionar e invitar a la reflexión. Por esta razón, creemos que ambas novelas gráficas constituyen propuestas idóneas para trabajar la educación literaria, democrática y por la igualdad: siguiendo las directrices de la pedagogía crítica, Cuerda de presas y El ala rota permiten demostrar, por una parte, hasta qué punto la construcción del conocimiento está condicionada por relaciones de autoridad y de poder y, por otra parte, que la literatura puede ser un instrumento de oposición y subversión de estas relaciones desiguales, propiciando, en este caso, la rehabilitación de un imaginario femenino agentivo. Llevar a cabo estos planteamientos pedagógicos de promoción de la lectura en aulas y bibliotecas, en última instancia, contribuiría a robustecer el proceso de canonización y de legitimación culturalista del cómic.

\section{Notas}

1. Cuerda de presas se publica poco después de la llegada a las librerías españolas de la traducción de Persépolis (2002-2004), de Marjane Satrapi, pionera en la introducción del imaginario femenino en las novelas gráficas sobre conflictos bélicos de naturaleza testimonial.

2. Se trata de trabajos como Priya's Shakti (2014), de Ram Devineni i Dan Goldman, Dragonslippers: This Is What an Abusive Relationship Looks Like (2006, Quiéreme bien. Una historia de maltrato), de Rosalind B. Penfold, À la folie (2009, Con locura, amor y malos tratos), de Sylvain Ricard y James, Becoming Unbecoming (2015, Una entre muchas), de Una. 3. Debe señalarse que los trabajos de Martínez y García y de Altarriba y Kim que aquí analizamos tienen sendos antecedentes en relatos protagonizados por hombres: Cuerda de presos (1954) de Tomás Salvador, Premio Nacional de Literatura, de la cual Pedro Lazaga realizó una adaptación cinematográfica el año siguiente; y El arte de volar (2009), de Antonio Altarriba y Kim, en el que Altarriba narra la historia de su padre, que obtuvo el Premio Nacional del Cómic.

4. El proceso de reparación ha tenido continuidad en Estamos todas bien (2017), la novela gráfica feminista de Ana Penyas consagrada a la memoria de las mujeres que sufrieron en silencio la posguerra y, a su vez, en el reconocimiento con el Premio Nacional del Cómic en 2018 por parte de la institución de la historieta en España a este trabajo, premiando por primera vez una autora.

5. Cabe subrayar que, por ahora, "todavía no existen novelas gráficas sobre el tema escritas o ilustradas por mujeres" (Crippa, 2019).

6. Max Estrella, protagonista de Luces de Bohemia, de Ramón María del Valle Inclán, explica esta deformación en su ebriedad. El protagonista borracho, junto a su amigo Don Latino de Hispalis, reflexiona sobre la sociedad de la época y la estética que la describe: "MAX: Los héroes clásicos reflejados en los espejos cóncavos dan el Esperpento. El sentido trágico de la vida española sólo puede darse con una estética sistemáticamente deformada" $(1998,162)$.

7. En el epílogo del El ala rota, Altarriba explica que empieza a pensar en escribir la historia de Petra a raíz de una entrevista en la que estaba promocionando El arte de volar y 
la que una periodista le pregunta acerca de la historia de su madre: “ $i$ su mamá ?". Una mujer formuló la pregunta desde el fondo de la sala. Y la respuesta me pareció fácil. Al menos al principio. Porque, conforme contestaba, los argumentos se me antojaban menos sólidos, producto de un discurso convencional, absolutamente superficiales. Notaba cómo me iba enfangando en mis propias frases. "Se trata de la vida de mi padre, es normal que mi madre tenga un papel secundario..." "no había una gran conexión ideológica entre ellos..." "ella no se implicó en los desafíos políticos de la época...". Cuando terminé de hablar, la expresión en el rostro de mi interlocutora confirmó la sensación de que no había satisfecho su curiosidad. Más aún, la pregunta abrió un cuestionamiento, que fue ahondándose con el tiempo, sobre mi obra, incluso sobre mis relaciones familiares y la forma en la que, desde hacía décadas, venía explicándomelas, encajadas en un molde forjado en la infancia y prácticamente inalterado desde entonces" (257).

8. La inclusión de fotografías para representar recuerdos es un recurso comúnmente usado en el cómic contemporáneo testimonial y memorialista. A través de este recurso se añade veracidad al relato, como rastro tangible de la vida y de los acontecimientos históricos.

\section{Referencias bibliográficas}

Altarriba, A. y Kim. (2016). El ala rota. Barcelona: Norma Editorial.

Arfuch, L. (2013). Memoria y autobiografía. Exploraciones en los límites. Buenos Aires: Fondo de Cultura Económica de Argentina.

Aróstegui, J. (2006). “Traumas colectivos y memorias generacionales: el caso de la guerra civil”. En: Aróstegui, J.; Godicheau, F. (eds), Guerra Civil. Mito y memoria. Madrid: Marcial Pons.

Auroy, V. (2019). "Une vision sexuée de l'Histoire contemporaine espagnole à travers deux œuvres d'Antonio Altarriba et Kim, El arte de volar et El ala rota". En: Cahiers de civilisation espagnole contemporaine, [En línea], no 22, disponible en: http://journals. openedition.org/ccec/7916

Behiels, L. (2020). "Un modo de ser mujer: género y posguerra en el cómic El ala rota de Antonio Altarriba y Kim (2016)". En: Amman, E. et alt. (eds), Con la posguerra en el retrovisor: las representaciones culturales del periodo franquista en la democracia (19752018), Madrid-Frankfurt: Iberoamericana- Vervuert.

Bergès, K. (2012). "La nacionalización del cuerpo femenino al servicio de la construcción de la identidad nacional en las culturas políticas falangistas y franquistas". En: Mélanges de la Casa de Velázquez, no 20, pp. 91-103.

Bourdieu, P. (2000). La dominación masculina. Barcelona: Anagrama.

Butler, J. (2009). Frames of War. When is life griable? London-New York: Verso.

Celso, P.; Carlos, M. C. (2016). "Quadrinhos como mídia: A narrativa histórica e poética de El Arte de Volar e El Ala Rota”. En: Esferas, vol. 5, no 9, pp. 33-43.

Crippa, F. (2019). "El tratamiento de los personajes femeninos en algunas novelas gráficas contemporáneas sobre la Guerra Civil española”. En: Cahiers de civilisation espagnole contemporaine [En línea], no 22, disponible en: https://doi.org/10.4000/ccec.8310 
Dounovetz, S. y Roca, P. (2010). El ángel de la retirada. Bang Ediciones.

Di Liscia, M. H. (2007). “Género y memorias”. En: La Aljaba, Segunda época, vol. xi, pp. 141-166.

García, J. y Martínez, F. (2005). Cuerda de presas. Bilbao: Astiberri.

Ginzburg, C. (1992). “Just One Witness”. En: Friedlander, S. (ed.) Probing the Limits of Representation. Nazism and the 'Final Solution'. Cambridge, Massachusetts: Harvard University Press, pp. 82-96.

Giroux, H. (2018) [2015]. Pedagogía crítica para tiempos difíciles. Traducción de María Rosales. Madrid: Editorial Mapas Colectivos.

Gyssels, E. (2019). La vida oculta de las mujeres de la posguerra. El ala rota (2016), de Antonio Altarriba (y Kim), y Estamos todas bien (2018), de Ana Penyas. Trabajo de máster presentado en la Universidad de Gent. Disponible en: https://lib.ugent.be/fulltxt/ RUG01/002/790/062/RUG01-002790062_2019_0001_AC.pdf

Hafter, L. (2014). "Representaciones de la infancia en Cuerda de presas: trazos de identidad". En: Kamchatka, no 3, pp. 97-117.

Matly, M. (2018). El cómic sobre la Guerra Civil. Madrid: Cátedra.

Mitaine, B. (2010). "Cuerda de presas ou les prisons de femmes sous Franco dans la bande dessinée espagnole”. En Fisbach, E.; Dumas, C. (ed). Récits de prison et d'enfermement. Angers: Presses de l'Université d'Angers, pp. 319-327.

Morcillo Gómez, A. (2016). En cuerpo y alma. Ser mujer en tiempos de Franco. Madrid: Siglo XXI de España.

Piedras, P. (2017). "Recuerdos, emoción, representación. Formas de la memoria de la represión en la España actual”. En: Studia Romanica Posnaniensia, vol. 44, n 1, pp. 63-73.

Said, E. W. (2004). Humanism and Democratic Criticism. Columbia: Columbia University Press.

Suárez, C. (2018). "Memoria histórica en viñetas: representaciones de la Guerra Civil Española a través de la narrativa gráfica y los testimonios familiares”. En: Caracol, no 15 , pp. 286-306.

Todorov, T. (2014) [2008]. El miedo a los bárbaros. Traducción de Noemí Sobregués. Barcelona: Círculo de Lectores.

Troncoso Pérez, L. E. y Piper Shafir, I. (2015). "Género y memoria: articulaciones críticas y feministas”. En: Athenea Digital, vol. 15, no 1, pp. 65-90.

Valle-Inclán, R. (1998). Luces De Bohemia: Esperpento. Edited by Alonso Zamora Vicente, Madrid: Espasa-Calpe.

Abstract: This work proposes a reading, framed in the intersection of memory and gender studies, of two Spanish graphic novels: Cuerda de presas (2005), by Fidel Martínez and Jorge García, and El ala rota (2016), by Antonio Altarriba and Kim. In order to subvert the hegemonic androcentric historical memory narratives, both novels compose the political and social space of women during the Civil War and Francoism and take charge of their symbolic representation. Through the analysis of differences and contacts between 
the narrative elements of written literature and those of the graphic medium, it will become evident that the determining impact of patriarchal power and gender violence on women's life trajectories is represented through female corporality; a representation that seeks an ethical response from the reader. The hermeneutic discourse pursues a didactic purpose. Following critical pedagogy, it will be argued that the works illustrate the extent to which power relations intervene in the construction of knowledge and that graphic literature can be an instrument of opposition and subversion of these unequal relationships, propitiating, in this case, the rehabilitation of an agentive female imagery.

Keywords: Graphic novel - Memory - Civil War - Francoism - Sexist violence.

Resumo: Este trabalho propõe uma leitura, emoldurada na intersecção entre os estudos de memória e gênero, de duas graphic novels espanholas: Corda de Presa (2005), Fidel Martínez e Jorge García, e El wing rota (2016), de Antonio Altarriba e Kim. A fim de subvertendo contas de memória histórica androcêntrica hegemônica, ambos constroem espaço político e social das mulheres durante a Guerra Civil e o Franquismo e são feitos cobrar de sua representação simbólica. Analisando diferenças e contatos entre elementos narrativos da literatura escrita e os do meio gráfico, serão demonstrados que o impacto decisivo do poder patriarcal e da violência sexista nas trajetórias os sinais vitais das mulheres são representados através da corpo feminina, buscando ativar uma resposta ética do leitor. Discurso hermenêutico busca um propósito ensino: seguindo pedagogia crítica, argumentar-seá que as obras ilustram o quão longe relações de poder estão envolvidos na construção do conhecimento e como literatura gráfica pode ser um instrumento de oposição e subversão dessas relações promovendo, neste caso, a reabilitação de uma mulher feminina agentiva imaginária.

Palavras chave: Graphic novels - Memória - Guerra Civil - Franquismo - violencia sexista. [Las traducciones de los abstracts fueron supervisadas por el autor de cada artículo] 